\title{
Socio-economic status and population density risk factors for psychosis: prospective incidence study in the Maltese Islands
}

\author{
Nigel Camilleri MD MRCPsych DCP, ${ }^{1 *}$ Anton Grech MD MSc MRCPsych ${ }^{2 *}$ \\ and Rachel Taylor East MD MSc ${ }^{3}$
}

'Child and Adolescent Mental Health Service, Northern Deanery and Institute of Neuroscience, Newcastle University, Newcastle, UK, email calutta001@yahoo.com; ${ }^{2}$ Mount Carmel Hospital, Attard, Malta, and University of Malta, Msida, Malta; ${ }^{3}$ Mount Carmel Hospital, Attard, Malta *The first two authors contributed equally to the preparation of this paper

$\mathrm{M}$ alta is an archipelago (with three inhabited islands) in the Mediterranean Sea. According to the 2006 census, Malta has a population of just over 400000 and is the eighth most densely populated country in the world (1272 persons $/ \mathrm{km}^{2}$ ) and the most densely populated of the member states of the European Union (EU). The most densely populated town in Malta is Senglea, with 22744 persons $/ \mathrm{km}^{2}$ (situated in the Southern Harbour Area). In comparison, Malta's sister island, Gozo, has a density of 422 persons $/ \mathrm{km}^{2}$. Over $92 \%$ of the population lives in urban areas.

There are three National Health Service units that offer treatment for psychiatric patients. The largest is Mount Carmel Hospital, with 569 beds. Smaller units exist within two general hospitals: Mater Dei Hospital (on the main island) and Gozo General Hospital.

A prospective study of the residents of a large metropolitan city in Brazil found that the incidence of psychosis was 15.8 per 100000 person-years at risk $(95 \% \mathrm{Cl} 14.3-$ 17.6) (Menezes et al, 2007). This figure is lower than that reported in most epidemiological studies. Findings from the three-centre AESOP study (Kirkbride et al, 2006), a UK epidemiological study, concluded that the incidence of all psychotic disorders was 34.8 per 100000 person-years (95\% Cl 32.1-37.8). In this study it was suggested that environmental effects may interact with genetic factors in the aetiology of psychosis. Kirkbride et al found that the incidence of psychosis varied with place, in that the incidence in the south-east of London (54.5 per capita) was double that of Nottingham (25.1 per capita) and Bristol (22.0 per capita). The point prevalence and lifetime risk have nonetheless been found to be similar in different countries, at, respectively, $140-460$ per 100000 and approximately $1 \%$ of the population (Kendler et al, 1996).

A number of studies have assessed the relationship between urbanisation and psychosis. A longitudinal birth cohort study carried out in the Netherlands concluded that urban birth was linearly associated with schizophrenia, and that this effect appeared to be increasing over successive generations (Marcelis et al, 1998). Another study concluded that individuals who were exposed to urbanisation at birth as opposed to those exposed to urbanisation at the time of onset of illness where at a higher risk of developing schizophrenia (Marcelis et al, 1999). A follow-up study of 4.4 million people in Sweden concluded that urbanisation is associated with a 68-77\% greater risk of developing psychosis for both men and women (Sundquist et al, 2004).

The things that contribute to urban stress include noise, pollution, health behaviours and social factors such as social fragmentation, social isolation and social inequality (Van Os et al, 2000; Van Os, 2004). The incidence of schizophrenia increases consistently with increasing levels of unbanisation in a dose-response fashion. This not only suggests statistical association but also causality (Van Os, 2004).

Research on birth cohorts in Finland has suggested that the increase in the number of patients suffering from psychosis is likely due to socio-economic factors (Haukka et al, 2007).

The aim of the present study was to determine the incidence of patients suffering from psychosis and requiring admission to hospital. We also intended to gain further epidemiological information, specifically in relation to population density and socio-economic status, as well as ethnicity, and to examine any differences between the six districts of the Maltese Islands. Based on the evidence from previous studies briefly reviewed above, we hypothesised that a higher incidence of psychosis would be found in the lower socioeconomic region, the more densely populated regions and among 'irregular' migrants.

\section{Method}

This was a prospective cross-sectional study of the incidence of psychosis in patients requiring admission to hospital. The sample comprised all patients newly admitted, with a diagnosis of psychosis, to a psychiatric ward at any of the three government hospitals between 1 May 2007 and 30 April 2008. There were no exclusion criteria related to age, gender or ethnicity.

At admission, the senior doctor established whether the patient had a psychosis. The patient was then seen by the consultant psychiatrist and multidisciplinary team (MDT) to confirm or dismiss the diagnosis. Only people with a diagnosis of psychosis by the MDT were included in the study. 


\section{The regions}

Malta is divided into six regions: the Southern Harbour Area, the Northern Harbour Area, the South-East District, the Western District, the Northern District and Gozo and Comino District. The incidence was calculated for each region and then compared statistically.

\section{Data protection}

All patients were invited to participate in the study and were free to decline. Informed consent was given. They were informed that all data collected would be anonymous and confidential and that this study would not negatively or positively affect the treatment they received in hospital.

This study was approved by the relevant authorities.

\section{Statistics}

All data were input into Microsoft Excel and analysed using SPSS. Confidence intervals were calculated using the standard formula for rates. Gender- and age-specific direct standardisation of data from the migrant on the native population was carried out.

\section{Results}

The study cohort comprised 115 people. Satisfactory data were available on 111 patients (96.5\%), 67 of whom were male and 44 female. The mean age at index admission was 41.4 years ( $95 \% \mathrm{Cl} 38.3-44.0)$. The ages ranged from 16 to 87 years.

The incidence of patients with psychosis requiring admission to any hospital on the Maltese Islands was 26.0 per 100000 . The incidence of patients admitted to hospital diagnosed with a non-affective psychosis (schizophrenia) was 15.4 per $100000(95 \% \mathrm{Cl} 13-21)$, while the incidence of affective psychosis was 7 per 100000 (95\% Cl 5-10) and other types of psychosis (organic and drug induced) 4 per 100000 (95\% Cl 2-6) (Table 1). The difference between each group is statistically significant.

The epidemiological results were further analysed by district. The largest incidence of psychosis was found in the Southern Harbour Area (32.1 per 100000 person-years at risk). The most densely populated area in Malta (the Northern Harbour Area) was found to have an incidence of 28.3 per 100000 . These results were significantly differ-

Table 1 Number of patients admitted

\begin{tabular}{lccc}
\hline Diagnosis & New cases & Males & Females \\
$\begin{array}{c}\text { Organic disorders, delusions, } \\
\text { hallucinations or catatonic } \\
\text { stupor }\end{array}$ & $4(3.6 \%)$ & $2(50 \%)$ & $2(50 \%)$ \\
$\begin{array}{c}\text { Schizophrenia and } \\
\text { delusional disorders }\end{array}$ & $49(44.1 \%)$ & $27(55 \%)$ & $22(45 \%)$ \\
$\begin{array}{c}\text { Acute and transient } \\
\text { psychotic disorders }\end{array}$ & $18(16.2 \%)$ & $9(50 \%)$ & $9(50 \%)$ \\
$\begin{array}{c}\text { Schizoaffective disorders } \\
\text { Psychotic disorder due to } \\
\text { psychoactive substance use }\end{array}$ & $12(10.8 \%)$ & $11(91 \%)$ & $1(9 \%)$ \\
$\begin{array}{c}\text { Bipolar affective disorder; } \\
\text { current episode manic with } \\
\text { psychotic symptoms }\end{array}$ & $12(10.8 \%)$ & $8(75 \%)$ & $4(25 \%)$ \\
$\begin{array}{c}\text { Severe depressive episode } \\
\text { with psychotic symptoms }\end{array}$ & $13(11.7 \%)$ & $8(62 \%)$ & $5(38 \%)$ \\
\hline
\end{tabular}

Table 2 Incidence of psychosis by district of Malta

$\begin{array}{lcl}\text { District } & \begin{array}{l}\text { No. of patients newly } \\ \text { admitted with psychosis }\end{array} & \begin{array}{l}\text { Incidence per } \\ 100000(95 \% \mathrm{Cl})\end{array} \\ \text { Southern Harbour } & 32 & 32.1(31.9-32.3) \\ \text { Northern Harbour } & 38 & 28.3(28.1-28.4) \\ \text { Western } & 8 & 20.1(19.9-20.2) \\ \text { South-East } & 10 & 20.9(20.8-21.1) \\ \text { Northern } & 11 & 22.4(22.2-22.6) \\ \text { Gozo and Comino } & 10 & 25.6(25.3-25.9) \\ \text { Irregular immigrants } & 6 & \text { Approximately } 400 \\ & & (379.8-420.2) \\ \text { Malta (national total) } & 115 & 26.0(25.9-26.1)\end{array}$

ent from the much lower incidence rates in the less densely populated districts. Gozo and Comino District was found to have a similar incidence to that of the mainland, at 25.6 per 100000 , although still statistically different, as indicated by the confidence intervals in Table 2.

Six of the patients (5\%) were irregular migrants. Data drawn from the Malta National Statistics Office show that in 2007 just over 1500 immigrants landed in Malta. The average stay for an irregular migrant is around 12 months, so an approximate estimate for the incidence of psychosis in irregular immigrants is 400 per 100000 person-years at risk. Even after adjustment for age and gender, rates for irregular migrants were found to be elevated. After direct standardisation, the weighted incidence for those aged 16-18 years was 49. For those aged over 19 years, if the Maltese population had the same risk of psychosis as the migrants we would have had 660 patients.

\section{Discussion}

The incidence of psychosis found in this study of the Maltese population is similar to that reported in other epidemiological studies. In our study the incidence differed statistically across the districts of the Maltese Islands. This highlights the important role urbanisation, socio-economic status and migration have in the aetiology of psychosis.

Sociological studies describe the Western District, where the incidence of psychosis was lowest, as the district with highest proportion of academic achievers. The Southern Harbour Area, where there was the highest incidence of psychosis, has the most residents in the lowest socio-economic group, with $41 \%$ of residents having no schooling (Camilleri, 2001). The Northern Harbour Area has the highest population density and the second highest incidence of psychosis.

The Gozo and Comino District has a much lower population density, yet the incidence was similar to that on Malta outside the Harbour Areas. This may be due to easier access to psychiatric services. However, it may also be that people living in this small community are more aware of stigma and discrimination, leading to people waiting longer before seeking medical attention. Symptoms may then be more severe, requiring hospitalisation. High expressed emotion, which is often a feature of closely knit families and extended families, could also account for the above results. Another explanation may be the smaller genetic pool.

The incidence of psychosis among irregular immigrants was very high when compared with that of the general 
Maltese population and that of other studies. Clinically, one of the most consistent findings among immigrant ethnic groups in Western Europe is an increase in the incidence rate of psychosis. A recent meta-analysis has confirmed that migration is a risk factor for schizophrenia that cannot be solely explained by selection (Cantro-Grae \& Shelton, 2005; see also Veiling et al, 2008).

\section{Limitations}

Our study excluded those suffering from a form of psychotic illness who were treated in the community. Nonetheless, since the Maltese National Health Service does not have an urgent care and home management team, we can expect that most patients suffering from a first episode of psychosis would be admitted to hospital.

The authors acknowledge that this study may suffer from the ecological fallacy: the sample population may not be truly representative of the target population. So the results should be interpreted with care.

Another limitation was that we did not include patients admitted to a private hospital, but, when the study was carried out, the private sector had no admitting units specifically for psychotic patients.

Data were solely collected from medical files; that is, with no interviews of the admitting doctors or patients themselves.

\section{Clinical implications}

The results of this study highlight that the incidence of psychosis is variable. In Malta, as in other countries, urbanisation, low socio-economic status and immigration are potential risk factors in the aetiology of psychosis. Higher educational attainment may be a protective factor. Awareness of this by clinicians and service providers can lead to better provision and planning of services.

\section{Acknowledgements}

We would like to thank Dr Neville Calleja MD MSc for his input of the statistical data.

\section{References}

Camilleri, F. (2001) A Day in Her Life: Insights into the Social and Economic Contribution of Maltese Women. Commission for the Advancement of Women, Ministry of Social Policy, Malta.

Cantro-Grae, E. \& Shelton, J. P. (2005) Schizophrenia and migration: a meta-analysis review. American Journal of Psychiatry, 162, 12-24.

Haukka, J., Suvisaari, J., Varilo, T., et al (2001) Regional variation in the incidence of schizophrenia in Finland: a study of birth cohorts born from 1950-1969. Psychological Medicine, 31, 1045-1053.

Kendler, K. S., Gallagher, T. J., Abelson, J. M., et al (1996) Lifetime prevalence, demographic risk factors, and diagnostic validity of nonaffective psychosis as assessed in a US community sample: the National Comorbidity Survey. Archives of General Psychiatry, 53, 1022-1031.

Kirkbride, J. B., Fearon, P., Morgan, C., et al (2006) Heterogeneity in incidence rates of schizophrenia and other psychotic syndromes. Archives of General Psychiatry, 63, 250-258.

Marcelis, M., Navarro-Mateu, F., Murray, R., et al (1998) Urbanization and psychosis: a study of 1942-1978 birth cohorts in the Netherlands. Psychological Medicine, 28, 871-879.

Marcelis, M., Takei, N. \& Van Os, J. (1999) Urbanisation and risk for schizophrenia: does the effect operate before or around the time of illness onset? Psychological Medicine, 29, 1197-1203.

Menezes, P. R., Scazufca, M., Busatto, G. F., et al (2007) Incidence of first-contact psychosis in Sao Paulo, Brazil. British Journal of Psychiatry, 191, 102-106.

Sundquist, K., Frank, G. \& Sundquist, J. (2004) Urbanisation and incidence of psychosis and depression: follow-up study of 4.4 million women and men in Sweden. British Journal of Psychiatry, 184, 293-298.

Van Os, J. (2004) Does the urban environment cause psychosis? British Journal of Psychiatry, 184, 287-288.

Van Os, J., Driessen, G., Gunther, N., et al (2000) Neighbourhood variation in incidence of schizophrenia. Evidence for person-environment interaction. British Journal of Psychiatry, 176, 243-248.

Veiling, W., Susser, E., Van Os, J., et al (2008) Ethnic density of neighbourhoods and incidence of psychotic disorders among immigrants. American Journal of Psychiatry, 165, 66-73.

\title{
Collaboration between traditional healers and psychiatrists in Sudan
}

\author{
E. A. Sorketti, ${ }^{1}$ N. Z. Zuraida ${ }^{2}$ and M. H. Habil ${ }^{3}$
}

${ }^{1}$ Psychiatrist, Department of Psychological Medicine, Faculty of Medicine, University of Malaya, Kuala Lumpur, Malaysia, email ehabsorketti@yahoo.com; ${ }^{2}$ Consultant Psychiatrist, Department of Psychological Medicine, Faculty of Medicine, University of Malaya; ${ }^{3}$ Head, Department of Psychological Medicine, Faculty of Medicine, University of Malaya$$
\text { he importance of traditional healing in low- and }
$$
middle-income countries cannot be underestimated. It is generally perceived as part of the prevailing belief system and traditional healers are often seen as the primary agents for psychosocial problems in these countries; estimates of their service share range from $45 \%$ to $60 \%$ (World Health Organization, 1992). The World Health Organization (2000) estimated that $80 \%$ of people living in rural areas in low- and middleincome countries depend on traditional medicine for their health needs.
In Sudan, a country with a mixed Arab/African culture, traditional healing is the most common method of treating people with mental illness, mostly because it is usually far cheaper than medical treatment (Elsafi \& Baasher, 1981-94) but also because of the inaccessibility of medical services and lack of awareness among the population. Baasher (1994) suggested that the holistic approach of traditional healing may lead to long-term stability of health. There is, though, no regulation of traditional healers and consequently many cases of abuse have been reported. Sorketti (2009) mentioned that the treatment of severe mental disorders is not available at 